\title{
Preparation and Control Efficiency of Seed Coating Agent by Antagonistic Actinomycetes Against Clubroot
}

\author{
Yating Song ${ }^{1}$, Yun Huang ${ }^{1}$, Xuegui Wang ${ }^{1}$, Jing Shang ${ }^{1} \&$ Hui Yang ${ }^{1}$ \\ ${ }^{1}$ Department of Plant Pathology, Sichuan Agricultural University, Chengdu, China \\ Correspondence: Yun Huang, Department of Plant Pathology, Sichuan Agricultural University, No.211 Huimin \\ Road of Wenjiang district, Chengdu 611130, China. E-mail: 5787huangyun@sina.com.cn
}

Received: December 26, 2013 Accepted: January 22, 2014 Online Published: February 15, 2014

doi:10.5539/jas.v6n3p132 URL: http://dx.doi.org/10.5539/jas.v6n3p132

\begin{abstract}
In order to better use the antagonistic actinomycetes strain F22-29, the formula of the seed coating with the fermentation broth of F22-29 strain was screened and optimized by two orthogonal designed tests. The results showed that the best formula of seed coating agent was $1 \%$ sodium lignin sulfonate: $2 \%$ carboxy methylcellulose sodium: $2 \%$ dextrin. Compared with the root irrigation of the fermentation broth, the control efficiency of the seed coating against Rape Plasmodiophora brassicae was increased by $38.11 \%$, and that of the seed coating against the Clubroot Disease in Brassica napus was increased by 63.16\%. For Chinese cabbage coated seed, the control efficiency was increased by $15.78 \%$.
\end{abstract}

Keywords: antagonistic actinomycetes, seed coating, clubroot, control effect

\section{Introduction}

The club-root disease of cruciferous crops is caused by the Plasmodiophora brassicae Woron. It can cause the decline of cruciferae crop yield. The concept of "seed coating" was firstly proposed by the Soviet Union in the 1960s. The seed coating has been developed rapidly in western countries, such as Germany and American in 1970s (Wu et al., 2003). ZBS biological seed coating with antagonistic bacteria is the first biological seed coating agent in China, which has been applied in the rice, wheat, corn, cotton and other crops (Shao, 2000). The BA-biological seed coating which is mixed with Vivtorinox azotobacter, Bacterium anthracoides, Bacillus mucilaginosus, and Streptomyces jingyangensis, by which the output of wheat, corn and other crops was increased obviously (Fang, 2004, 2005). The biological seed coating agent HND1 which has made with the bioactive metabolite of Verticillium chlamydosporium HDQ18 has good control effect on the soybeancyst nematode (Du, 2009). It shows that a seed coating treatment consisting of K-165 xanthan gum and talc is the most effective in prevention and treatment of the cotton black root rot (Chariklia et al., 2011). Recently research suggested that bacillus strains have a good effect on controling clubroot, such as Bacillus subtilis XF-1 and Bacillus subtilis Bs2004 (He et al., 2008; Liu, 2008). It was concluded by Jing Wang that antagonistic actinomycetes A316, A10 and antagonistic fungi T1 can strongly inhibit the germination of dormant spores, and do better in controlling rape clubroot in pot experiment and field experiment (Wang et al., 2011). Many research showed that the growth of crop can be promoted by the biological seed coating of antagonistic, by which the incidence rate of various diseases was reduced and the crop yield was increased. It's safety and environment-friendly. It plays the important role in plant disease control that can't be replaced by the chemical agent. Study on biological seed coating can effectively solve the problem of the preparation for antagonistic bacteria, which can treat plant diseases combined with prevention. Applications of biological seed coating also become a new highlights in the field of biological control of soil borne diseases (Guo et al., 2009). In this study, the fermentation broth of the strain F22-29 was used as active component, to screen out the suitable additives and determine the final formulation of seed coating agents, to provide the basis for product development.

\section{Materials and Methods}

2.1 Organism

Antagonistic actinomycetes strain F22-29 was isolated from Plant Pathology Laboratory of Sichuan Agricultural University, and was stored at zero to four degrees celsius. According to the study, the antagonistic actinomycetes 
strain F22-29 was a mutant strain, it had a good control effect on clubroot in the field, the control efficiency was $59.99 \%$, it was improved by $29.32 \%$ than the original strain (Lin, 2012).

\subsection{Vegetable Varieties}

We chose the three kinds of cruciferous vegetable seeds for experiment. Rape seeds N102-5 was developed by Department of Crop Breeding and Genetics in Sichuan Agricultural University. Chinese cabbage seeds Early maturing No. Five and Brassica napus seeds Xiyuan No. Four were purchased.

\subsection{Mediums}

Millet medium: glucose, sodium chloride, peptone, calcium carbonate.

Dispersant: sodium lignosulfate, sodium dodecyl benzene sulfonate, sodium dodecylsulfate, tween.

Membrane agent: carboxymethylcellulose sodium, sodium alginate, soluble starch, polyving akohol, chitosan.

Filling compound: dextrin, diatomite, light calcium carbonate, kaolin.

\subsection{Screening of Auxiliary Agents}

At first, the actinomycete fermentation liquid F22-29 was mixed with 3\% filling compound, $2 \%$ dispersants, $1 \%$ membrane agent, and cultured at $25^{\circ} \mathrm{C}$ for 5 days. The control group was the untreated actinomycete fermentation liquid. In this experiment, the effects of various additiveson actinomycetes biological activity was determined by measuring the number of bacteria (living spores number), using the dilution method of plate counting (Guo, 2001).

\subsection{Determination of Seed Coating Formulation}

Selected the auxiliary agents which didn't affect the actinomycetes biological activity, used the orthogonal method $\mathrm{L}_{9}\left(3^{4}\right)$ to determine the type and dosage of adjuvants, in order to determine the final formulation of seed coating. Seed germination rate was the main index of experiment, other physical traits of preparation were secondary screening index. Took 100 tablets of rape coated seed, were placed in the Perti dishes which with double wet filter paper in it, at $25^{\circ} \mathrm{C}$ for moisture culture germination, uncoated seeds as blank control. Repeated for 3 times (Lu, 2003).

\subsection{Preparation and Coating}

Bene tritum selected auxiliary agents and sifted them, then mixed with the actinomycete fermentation liquid F22-29 with different proportion, and it was the seed coating sample. The seed coating agent and rape seed mixed, placed in a Petri dish so that the surface of seed coating agent solidified membrane (Zhang, 1997).

\subsection{Determination of Indexes}

Determination of seed coating indexes was carried out in accordance with the national standards of the people's Republic of China GB/T 17768-1999 (State Bureau of technical supervision of the people's Republic of China, 1999).

\subsection{Pot Experiments}

In pot experiments, we used the soil which was made of sterilized soil and spore suspension, so the clubroot symptom development was by artificial inoculation. There were 3 proposals, coated seeds, root irrigation with actinomycete fermentation liquid F22-29, and uncoated seeds as control. Each treatment had 3 pots, 15 plants per pot, 3 vegetable seed varieties were 27 treatments. After 60 days, the disease symptoms were assessed using a scale consisting of four classes according toYoshikawa Hiroaki: 0 (no symptoms), 1 (1\% 30\% of roots had smaller clubs), 2 (31\% 60\% of main root and lateral roots had clubs), $3(61 \% \sim 100 \%$ of roots had bigger clubs, plant growth might be impaired)(Yoshikawa Hiroaki,1989).

$\mathrm{DI}=\left(0 \mathrm{n}_{0}+1 \mathrm{n}_{1}+2 \mathrm{n}_{2}+3 \mathrm{n}_{3}\right)(100 / 3 \mathrm{Nt})$

$\left(\mathrm{n}_{0}-\mathrm{n}_{3}\right.$ is the number of plants in the indicated class and $\mathrm{N}_{\mathrm{t}}$ is the total number of plants tested.)

Control Efficiency $\%=\left[\left(\mathrm{DI}_{\text {control }}-\mathrm{DI}_{\text {treatment }}\right) / \mathrm{DI}_{\text {control }}\right] \times 100$

Incidence $\%=$ The number of diseased plants $/$ The total number of investigation $\times 100$

\subsection{Data Analysis}

Experimental data were analyzed using the LSD test $(\mathrm{P}<0.05)$ with significant difference analysis software DPS2006. 


\section{Results}

\subsection{Screening of Auxiliary Agents}

The results showed that tween was a dispersant which had minimal impact on the biological activity of actinomycete F22-29, but sodium dodecyl benzene sulfonate had the biggest influence. For membrane agent, chitosan had minimal impact on the biological activity of actinomycete F22-29, polyving akohol greatly affects the biological activity. Light calcium carbonate was a filling compound which had minimal impact on the biological activity of actinomycete F22-29, but kaolin had the biggest influence (Table 1). Considering the physical properties of auxiliaries, we screened out the following auxiliary agents for further test: sodium lignosulfate, sodium dodecylsulfate, tween (Dispersant). carboxymethylcellulose sodium, soluble starch (Membrane agent). dextrin, diatomite, light calcium carbonate (Filling compound).

Table 1. Effects of Auxiliary on the biological activity of Actinomycete F22-29

\begin{tabular}{lll}
\hline Kinds of Auxiliary agents & Name of Auxiliary agents & Colony number $(\mathrm{cfu} / \mathrm{mL})$ \\
\hline \multirow{2}{*}{ Dispersant } & sodium lignosulfate & $1.27 \times 10^{6} \mathrm{c}$ \\
& sodium dodecyl benzene sulfonate & $1.10 \times 10^{4} \mathrm{c}$ \\
& sodium dodecylsulfate & $1.15 \times 10^{7} \mathrm{c}$ \\
& tween & $3.19 \times 10^{7} \mathrm{c}$ \\
\hline & carboxymethylcellulose sodium & $1.59 \times 10^{8} \mathrm{abc}$ \\
& sodium alginate & $1.62 \times 10^{8} \mathrm{abc}$ \\
Membrane agent & soluble starch & $6.92 \times 10^{7} \mathrm{c}$ \\
& polyving akohol & $3.48 \times 10^{6} \mathrm{c}$ \\
& chitosan & $1.82 \times 10^{8} \mathrm{abc}$ \\
\hline \multirow{3}{*}{ Filling compound } & dextrin & $1.02 \times 10^{8} \mathrm{bc}$ \\
& diatomite & $1.89 \times 10^{8} \mathrm{abc}$ \\
& light calcium carbonate & $3.24 \times 10^{8} \mathrm{ab}$ \\
\hline CK & kaolin & $2.23 \times 10^{5} \mathrm{c}$ \\
\hline
\end{tabular}

Note: The different letters of the same series indicate the significant difference at $5 \%$ level $(\mathrm{P}<0.05)$, the same below.

\subsection{Determination of Seed Coating Formulation}

In the experiment, the first $\mathrm{L}_{9}\left(3^{4}\right)$ orthogonal test was used to determine the species of dispersant, membrane agent and filling compound. Table 3 showed that the dispersing agent had the maximum range (R), so it greatly affects the seed germination rate, the Sodium lignosulfate which had the maximum average value of factor level was choosed (K-mean). In contrast, seed germination rate was smaller influenced by membrane agent and filling compound, and the carboxymethylcellulose sodium and dextrin were choosed for the next step test. The final seed coating formulation was sodium lignosulfate, carboxymethylcellulose sodium and dextrin.

Table 2. Arrangement of the first $\mathrm{L}_{9}\left(3^{4}\right)$ orthogonal test

\begin{tabular}{llll}
\hline \multirow{2}{*}{ Level } & \multicolumn{2}{c}{ Factor } \\
\cline { 2 - 4 } & Dispersant & Membrane agent & Filling compound \\
\hline 1 & sodium lignosulfate & carboxymethylcellulose sodium & dextrin \\
2 & sodium dodecylsulfate & sodium alginate & diatomite \\
3 & tween & soluble starch & light calcium carbonate \\
\hline
\end{tabular}


Table 3. Results of the first $\mathrm{L}_{9}\left(3^{4}\right)$ orthogonal test

\begin{tabular}{ccccc}
\hline & \multicolumn{5}{c}{ Factor } & \multirow{2}{*}{ Relative germination rate (\%) } \\
\cline { 2 - 4 } Number & Dispersant & Membrane agent & Filling compound & \\
\hline 1 & 1 & 1 & 1 & $96.67 \mathrm{ab}$ \\
2 & 1 & 2 & 2 & $95.33 \mathrm{abc}$ \\
3 & 1 & 3 & 3 & $97.00 \mathrm{ab}$ \\
4 & 2 & 1 & 2 & $93.33 \mathrm{abc}$ \\
5 & 2 & 2 & 3 & $90.00 \mathrm{c}$ \\
6 & 2 & 3 & 1 & $91.00 \mathrm{abc}$ \\
7 & 3 & 1 & 3 & $95.67 \mathrm{abc}$ \\
8 & 3 & 2 & 1 & $96.33 \mathrm{a}$ \\
9 & 3 & 3 & 2 & \\
$\mathrm{~K}_{\text {avg1 }}$ & 96.33 & 95.22 & 94.67 & \\
$\mathrm{~K}_{\text {avg2 }}$ & 91.44 & 93.89 & 94.22 & \\
$\mathrm{~K}_{\text {avg3 }}$ & 95.33 & 94.00 & 94.22 & \\
$\mathrm{R}$ & 4.89 & 1.34 & 0.45 & \\
\hline
\end{tabular}

\subsection{Determination of Proportion}

The second $\mathrm{L}_{9}\left(3^{4}\right)$ orthogonal test was used to determine the auxiliary dosage. The results showed that dextrin had the maximum range(R), so the dosage of dextrin greatly affects the seed germination rate, the dosage of sodium lignosulfate and carboxymethylcellulose sodium had the smaller influence than dextrin. Considering the experimental results and the coating effect, we finalized the final seed coating dosage, it was $1 \%$ sodium lignosulfate: $2 \%$ carboxymethylcellulose sodium: $2 \%$ dextrin.

Table 4. Arrangement of the second $\mathrm{L}_{9}\left(3^{4}\right)$ orthogonal test

\begin{tabular}{cccc}
\hline \multirow{2}{*}{ Level } & \multicolumn{3}{c}{ Factor } \\
\cline { 2 - 4 } & Sodium lignosulfate (\%) & Carboxymethylcellulose sodium (\%) & Dextrin (\%) \\
\hline 1 & 2 & 3 & 3 \\
2 & 1.5 & 2.5 & 2.5 \\
3 & 1 & 2 & 2 \\
\hline
\end{tabular}

Table 5. Results of the second $\mathrm{L}_{9}\left(3^{4}\right)$ orthogonal test

\begin{tabular}{ccccc}
\hline \multirow{3}{*}{ Number } & \multicolumn{2}{c}{ Factor } & $\begin{array}{c}\text { Relative germination rate } \\
(\%)\end{array}$ \\
\cline { 2 - 4 } & Sodium lignosulfate & $\begin{array}{c}\text { Carboxymethylcellulose } \\
\text { sodium }\end{array}$ & Dextrin & $66.33 \mathrm{~d}$ \\
2 & 1 & 1 & 1 & $82.67 \mathrm{abc}$ \\
3 & 1 & 2 & 2 & $74.33 \mathrm{bcd}$ \\
4 & 1 & 3 & 3 & $74.33 \mathrm{~cd}$ \\
5 & 2 & 1 & 2 & $67.00 \mathrm{~d}$ \\
6 & 2 & 2 & 3 & $64.00 \mathrm{~d}$ \\
7 & 2 & 3 & 1 & $75.00 \mathrm{bcd}$ \\
8 & 3 & 1 & 3 & $83.33 \mathrm{~d}$ \\
9 & 3 & 2 & 1 & \\
$\mathrm{~K}_{\text {avg1 }}$ & 74.44 & 3 & 2 & \\
$\mathrm{~K}_{\text {avg2 }}$ & 68.44 & 71.89 & 63.89 & \\
$\mathrm{~K}_{\text {avg3 }}$ & 73.33 & 70.33 & 80.22 & \\
$\mathrm{R}$ & 6.00 & 74.00 & 72.11 & \\
\hline
\end{tabular}




\subsection{Determination of Indexes}

PH value of seed coating agent was 9.06 by determined the main physical and chemical properties (Table 6). Studies showed that it was not conducive to clubroot when soil $\mathrm{PH}>7.2$, therefore, the alkaline seed coating agent was helpful to reduce the harm of clubroot.

Table 6 . The determination results of indexes

\begin{tabular}{lllllll}
\hline Item & PH & $\begin{array}{l}\text { Effective } \\
\text { composition content } \\
(\%)\end{array}$ & $\begin{array}{l}\text { Suspension } \\
\text { rate (\%) }\end{array}$ & $\begin{array}{l}\text { Abscission } \\
\text { rate (\%) }\end{array}$ & $\begin{array}{l}\text { Low temperature } \\
\text { stability }\end{array}$ & $\begin{array}{l}\text { High temperature } \\
\text { stability }\end{array}$ \\
\hline Result & 9.06 & 83.45 & 98.17 & 6.19 & qualified & qualified \\
\hline
\end{tabular}

\subsection{Pot Experiment}

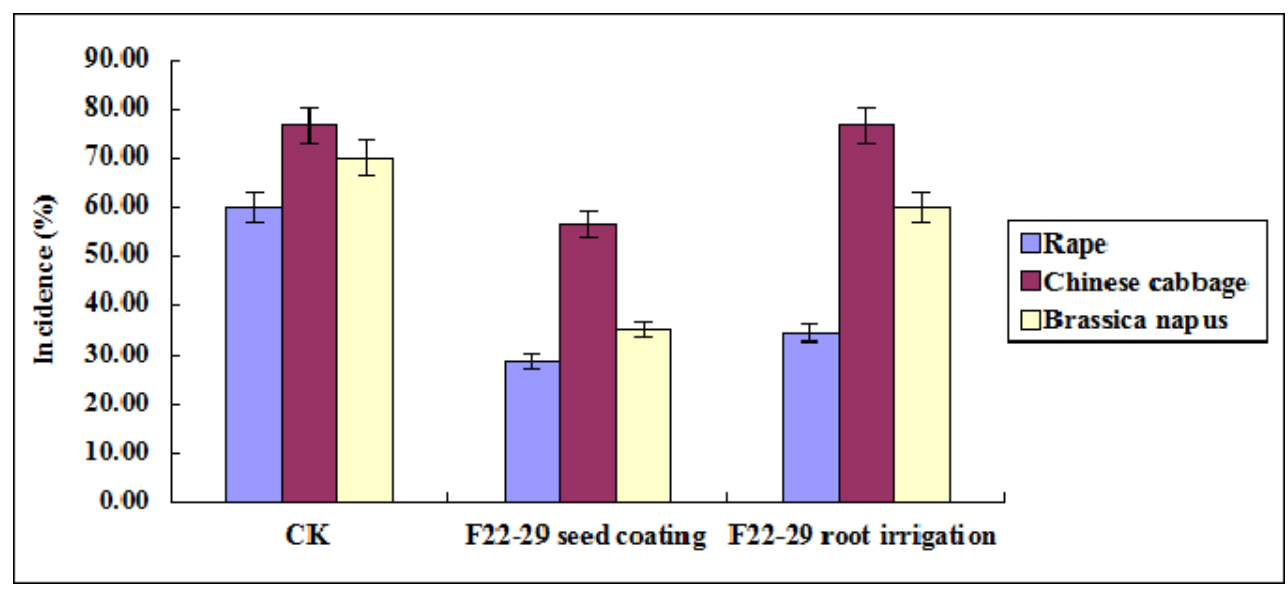

Figure 1. Incidence of pot experiment

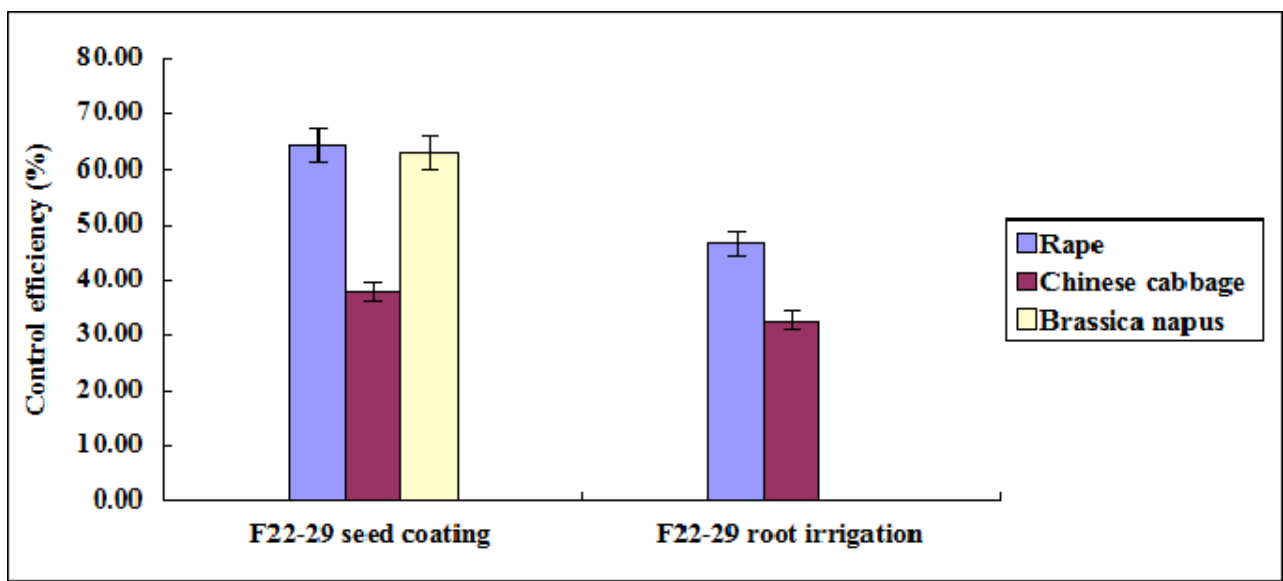

Figure 2. Control efficiency of pot experiment

In pot experiment, we prepared 3 kinds of coated seed (Rape, Chinese cabbage, Brassica napus). The results of pot experiment showed that the incidence of seed coating and root irrigation with actinomycete fermentation liquid F22-29 were both lower than the contorl which was only infected by pathogen. The incidence of antagonistic actinomycetes strain F22-29 seed coating and root irrigation against Rape clubroot were $28.57 \%$ and $34.29 \%$, they were lower than the incidence of control which was $60.00 \%$. The incidence of seed coating against Chinese cabbage clubroot were $56.67 \%$, it was decreased by $26.09 \%$ 
compared with the incidence of control. The incidence of seed coating and root irrigation with actinomycete fermentation liquid F22-29 against Brassica napus clubroot were $35.00 \%$ and $60.00 \%$, they were reduced by $50.00 \%$ and $14.29 \%$ compared with the incidence of control (Figure 1). The control efficiency of seed coating with actinomycete fermentation liquid F22-29 was significantly better than the root irrigation with it. The control efficiency of seed coating against Rape clubroot was up to $64.44 \%$, it was improved by $38.11 \%$ than control of root irrigation with actinomycete fermentation liquid F22-29. The control effect of seed coating against Chinese cabbage clubroot compared with actinomycete fermentation liquid F22-29 irrigation was improved up to $15.78 \%$, Brassica napus seed coating agent had a particularly good control effect on Brassica napus clubroot, the control efficiency was up to $63.16 \%$ (Figure 2).

\section{Discussion}

In the study of the prevention and treatment of clubroot disease, we now focus on the separation of rhizosphere soil and microorganism of chemical agents in order to control clubroot. The application effect of chemical agents has a relationship with the time, concentration and times for application, etc., so that the control efficiency is often difficult to assess. There are many different kinds of microorganisms in biological world. So far a few of them have been studied, such as Trichoderma spp., Streptomyces and Bacillus subtilis. It's far from enough for the exploration of microorganisms resources ( $\mathrm{Li}$ et al., 2013). Therefore, the development of biological actinomycetes seed coating agent not only uses microorganism resources to disease prevention and treatment, but also looks for a way to effective, convenient application method in field.

Resting sporangiums of crucifer clubroot disease spend summer and winter in soil and plant residue without compost manure. Resting sporangium has strong viability in soil, which could survive for $6 \sim 8$ years in general. It could spread for short distance, by water, nematode in soil, insect activity and farming operation in the field, or by the seedlings with disease and carrying plants for long distance transmission. Resting sporangium in soil can germinate and infect root hair under proper conditions. Therefore, seedling stage is the key period for clubroot disease prevention. Though the method of actinomycetes fermentation liquid coating could a protective film was formed around the seed and soil around the seed was colonized by the actinomyces, which inhibited the germination of dormant spores in the soil to a certain extent, thereby reducing the infection of zoospores on root hairs and reducing the incidence of clubroot.

This study was based on the actinomycetes fermentation liquid F22-29 as effective component which could control crucifer clubroot, the final seed coating formulation and proportion was confirmed by auxiliary agents screening. Through the experiment, we determined the sodium lignosulfate, carboxymethylcellulose sodium, dextrin as dispersing agent, membrane agent and filling compound, as the proportion of $1 \%: 2 \%: 2 \%$. The control effect of seed coating agent against Rape and Brassica napus clubroot reached more than $60 \%$, the control effect by seed coating against Chinese cabbage clubroot compared with actinomycete fermentation liquid F22-29 was improved $15.78 \%$. The control efficiency of seed coating with actinomycete fermentation liquid F22-29 was significantly better than the root irrigation with it, the results showed that there is also potential for exploiting the seed coating agent of actinomyce strain F22-29.

By the seed coating of antagonistic bacteria strain X203 and X189, Yan Zhang found that the control effect of seed coating treatment was higher than the root irrigation with ferment liquid, and the control effect of X203 coated seed on Chinese cabbage clubroot and Rape clubroot were higher than other treatments, up to $62.62 \%$ and $59.12 \%$ respectively (Zhang, 2010). It shows that the application of antagonistic strains of coating agent is an effective prevention method to control clubroot. Development of biocontrol actinomyces seed coating could cut the loss of manpower in the field. It is a more convenient and effective control method in prevention and treatment of clubroot.

In this experiment, the effective components of seed coating agent was only antagonistic, and other components were considered to adding into this agents such as elicitors, plant growth regulators, trace elements, in order to work at its best of seed coating agents. In addition, this experiment is a preliminary exploration on seed coating development with the active ingredient of the biocontrol actinomyces fermentation liquid, and the formulation and process of seed coating agents should be optimized in further. 


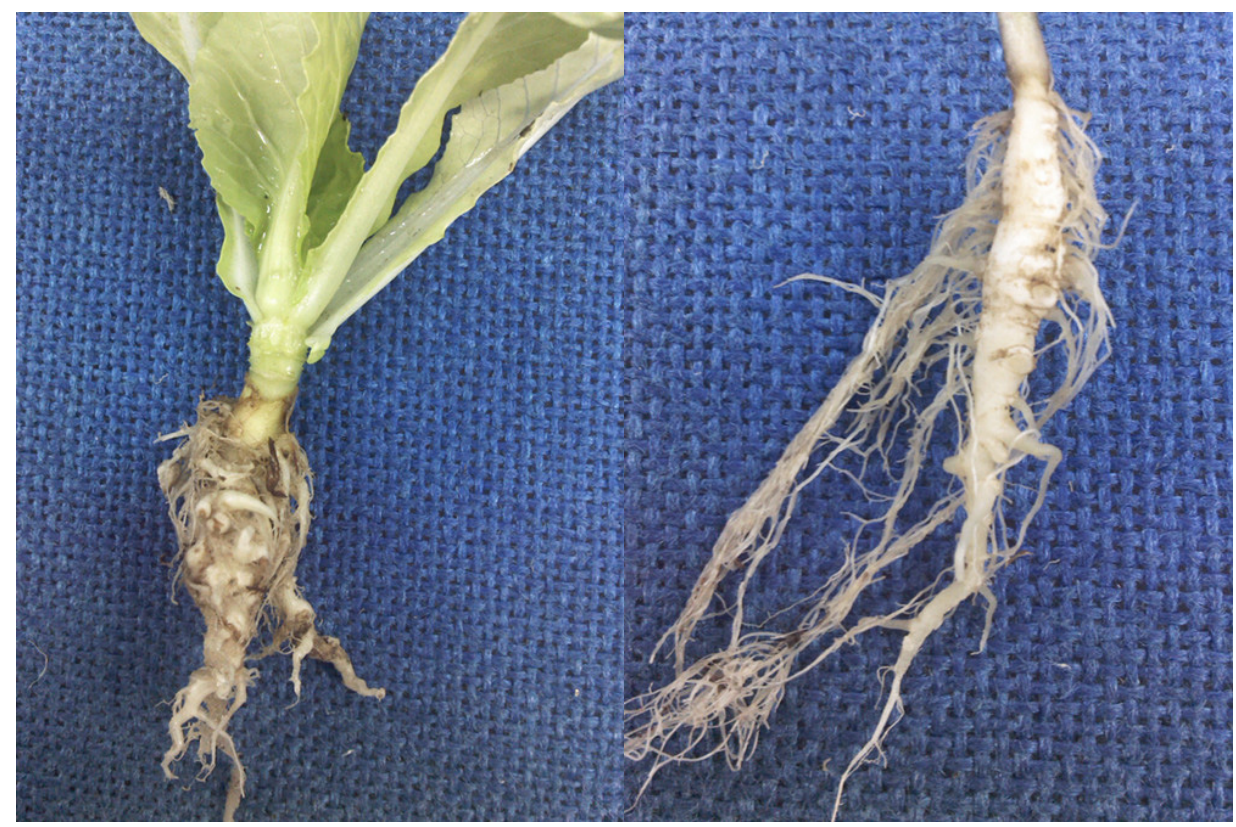

a

b

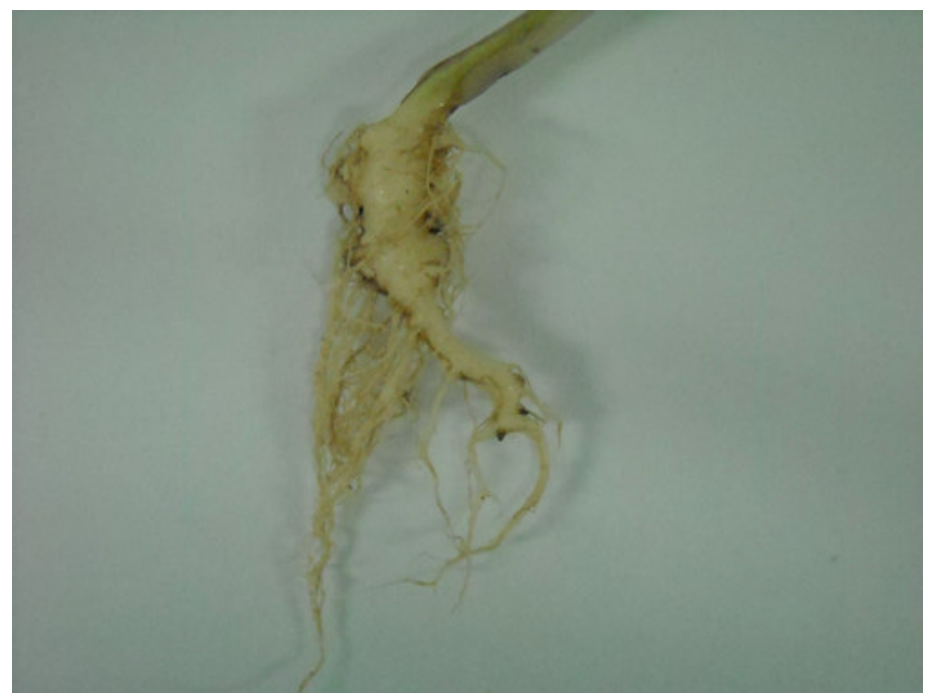

c

a: Chinese cabbage clubroot symptoms

b: Brassica napus clubroot symptoms

c: Rape clubroot symptoms

Figure 3. Clubroot symptoms of pot experiment

\section{Acknowledgements}

This work was supported by Commonweal Specialized Research Fund of China Agriculture, 201003029.

\section{References}

Chariklia, S., Ioannis, A. S., \& Iakovos, S. P. (2011). Evaluation of application methods and biocontrol efficacy of Paenibacillus alvei strain K-165, against the cotton black root rot pathogen Thielaviopsis basicola. $J$. Biological Control., 58, 68-73. http://dx.doi.org/10.1016/j.biocontrol.2011.04.002

Du, C. M., Li, H. Y., \& Li, X. M. (2009). Control Effects of HND1 Biological Seed Coating on Soybean Cyst Nematode. J. Soybean Science, 6(28), 1126-1129. 
Fang, X., Wang, Z. X., \& Feng, J. (2004). A preliminary study on the effect of wheat BA- biological seed coating agent. J. Journal of Microbiology, 2(24), 60-61.

Fang, X., Wang, Z. X., \& Feng, J. (2005). Effect of BA- biological seed coating agent on tomato. J. Shandong Agricultural Sciences, 1, 55-56.

Guo, N., Cheng, L. J., Duan, Y. X. (2009). Preparation and effects of biological seed coating on the soybean cyst nematode in soybean plots in Shenyang. J. Plant protection, 35(2), 158-162.

Guo, X. H., Xiao, C. G., \& Zeng, Y. (2001). Biological characteristics of Plasmodiophora brassicae. J. Journal of Southwest Agricultural University, 23(1), 7-9.

He, Y. Q., Xiong, G. R., \& Fan, C. M. (2008). Biological preparation capable of preventing and treating cruciferae club root and use there of. P.

Li, Z., Niu, Y. Z., \& Wu, Y. C. (2013). Research progress of clubroot. J. Journal of Southwest Agricultural University, 4, 1733-1737.

Lin, S. (2012). Screening and Mutation breeding of Antagonistic strains against Plasmodiophora brassicae. D. Sichuan Agricultural University, Master.

Liu, Y., Ke, S. Y., \& Huang, X. Q. (2008). Effect of Bacillus subtilis Strain Bs2004 on Promoting of Plant Health and Growth. J. Chinese Journal of Biological Control, 24(Suppl.), 46-49.

Lu, C. Y., \& Wu, W. J. (2003). A preliminary study on the rape seed coating treatment effect. J. Jiangsu Agricultural Sciences, 4, 21-22.

Shao, B. F. (2000). A microbial seed coating agent and its production method.

State Bureau of technical supervision of the people's Republic of China. (1999). GB/T 17768-1999. State Standard of the People's Republic of China. S. Beijing: China standards Press.

Wang, J., Huang, Y., \& Zhang, Y. (2011). Control of rapeseed clubroot by screened antagonistic microorganisms against Plasmodiophora brassicae. J. Chinese Journal of Oil Crop Sciences, 33(2), 169-174.

Wu, X. H., Liu, X. L., \& Wang, H. M. (2003). Progressing on the Study of Seed Coating Formulations in China. J. Pesticides, 5, 1-5.

Yoshikawa, H., \& Wang, S. (1989). Japan Cruciferae clubroot resistance breeding. J. China Vegetables., 03, $55-56$.

Zhang, W. J. (1997). The processing and application technologyof pesticides. M. Beijing, China Agricultural University press.

Zhang, Y. (2010). Screening of Antagonistic Strains Against Plasmodiophora Brassicae and Development of Seed Coating. D. Sichuan Agricultural University, Master.

\section{Copyrights}

Copyright for this article is retained by the author(s), with first publication rights granted to the journal.

This is an open-access article distributed under the terms and conditions of the Creative Commons Attribution license (http://creativecommons.org/licenses/by/3.0/). 